\title{
Current balancing of cascaded H-bridge converters for PV systems with partial shading
}

\begin{abstract}
The distributed generators connected to distribution network by means of power converters is rapidly increasing. If from one side, this generators offer an opportunity to provide ancillary services to the network, on the other side they might worsen the unbalancing of the network. The relevance of this topic is underlined by recent normative works and current discussions within several national and international standard bodies.

This paper studies a three-phase photovoltaic power system connected to the low voltage power grid. The power system consists of a photovoltaic source, and a DC/DC boost converter. The DC link is connected to the grid via a new cascaded H-bridge converter. With the proposed control strategy the photovoltaic source supplies to the grid the maximum power available with unity power factor. The control is formulated in the case of inhomogeneous irradiation and the line current symmetry is assumed as system requirement. The results of the numerical simulations are used to give evidence of the effectiveness of the proposed topology for the application to a building façade.
\end{abstract}

Index of terms: Distributed Generation, PV power systems, Modular Multilevel Converters, grid-interface converters.

\section{LIST OF SYMBOLS}

$C \quad$ DC capacitance of $h$-th $\mathrm{H}$-bridge module of $k$-th phase;

$a_{x} \quad$ real part of the complex number $a$

$a_{y} \quad$ imaginary part of the complex number $a$

i symmetrical component of three phase current;

$i_{0} \quad$ zero sequence component of three phase current;

$i_{p v, h, k} \quad h$-th PV current of Half-bridge module of k-phase;

$i_{k} \quad k$-th phase current;

$L \quad$ phase filter inductance;

$\mathbf{P}_{p v, \Sigma} \quad$ symmetrical component of equivalent PV sources;

$P_{p v, \Sigma, 0}$ zero sequence component of equivalent PV sources;

$\rho_{h, k} \quad$ switching function of $h$-th H-bridge module of $k$-th phase;

$s_{h, k} \quad$ switching function of $h$-th H-bridge module of $k$-th phase;

$v_{p v, h, k} \quad h$-th photovoltaic voltage of H-bridge module of $k$-th phase;

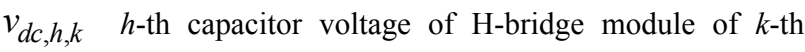
phase;

$\mathbf{v} \quad$ symmetrical component of line voltage;

$\mathbf{v}_{\Sigma} \quad$ symmetrical component of AC-side phase voltage of the cascaded H-Bridge;

\author{
$v_{\Sigma, 0} \quad$ zero sequence component of AC-side phase voltage of \\ the cascaded H-Bridge; \\ $\mathbf{W}_{d c, \Sigma}$ symmetrical component of equivalent energy stored in \\ the DC-capacitors; \\ $W_{d c, \Sigma, 0}$ zero sequence component of equivalent energy stored \\ in the DC-capacitors; \\ $\omega \quad$ angular frequency of the grid voltage.
}

\section{INTRODUCTION}

Distributed Generation (DG) and in particular Photovoltaic (PV) power systems are fast growing in installed power. PV plant installation, which span from few $\mathrm{kW}$ to $\mathrm{MW}$, were encouraged by incentives from Governments in industrial as well as in residential applications. The annual grow rate was also favoured by the reduction of panel costs. Indeed, as a consequence of market economy, the panel cost for high power PV plant was estimated of about $0.83 € / \mathrm{W}$ by 2012 .

PV power systems are connected to the distribution networks by means of power converters. The action of power converter on the distribution grid at the point of common coupling (PCC) can produce undesired effects on the grid in terms of power quality. Today, due to the high number of PV installations, this is increasingly a cause of concern. Among all of the power quality problems for low voltage (LV) distribution networks, harmonic distortion at lower and higher frequencies and voltage unbalancing, as a consequence of the variable magnitude of the current injected by PV systems, are the main causes of concern (Gallo et al., 2013).

PV power systems can be connected to LV distribution networks as single-phase, two-phase, or three-phase units. They can affect the network operations significantly. Although the most of the literature on PV systems in distribution networks studies PV systems as generators of balanced currents in a symmetrical three-phase system (Vecchiu et al., 2011), this assumption is sometimes not effective. This is the case, for instance, of single-phase or two-phase PV systems, as well as three-phase PV power sources operating under unbalanced power conditions of PV modules. As a consequence, current and voltage unbalance can produce relevant disturbances on electrical equipments connected to the grid.

The voltage unbalance of a poly-phase system is a condition in which the RMS values of the line voltage fundamental components are not the same and/or the phase angles between consecutive line voltages are not all equal to $120^{\circ}$. A three-phase system operating in unbalanced conditions can be studied by means of the "vector sequence" approach. Thus, the degree of the 
voltage unbalance is expressed as the ratio between the negative and zero sequence components with respect to the positive sequence component. Usually, only the negative sequence component is addressed, because it is often of more concern. Working Groups recommend for voltage unbalancing the same indexes used for harmonics, because of their similarity of thermal effects (Caramia et al. 2007).

According the recent Italian CEI 0-21 and German VDE 4105 standards, which deal with PV systems as resources of ancillary services contributing to network operation, some papers already proposed to use PV sources to reduce voltage unbalance controlling source's zero and negative sequence components (Caldon et al. 2012).

In this context, the use of cascade multi-level power converter technology has emerged recently as a very important alternative in the area of source energy control (Rodríguez et al., 2002, Malinowski et al., 2010). Cascaded multilevel converters present several remarkable features as high degree of modularity; high power quality, both input and output; high availability; and are suitable to use alternative power flow control algorithms. Studies on multilevel power converters for PV system were proposed in single-phase and three-phase application. In single-phase applications, the independent control of the DC-link voltage is used to both enable the tracking of the maximum power point for each string of PV panels and ensure system stability for the whole irradiance operating range (Villanueva et al., 2009, Chavarría et al., 2013). In three-phase PV applications, control methods for large scale power systems in unbalanced conditions were proposed (Morya et al., 2013).

According to the statement of DG in distribution network, this paper analyses a three-phase PV power system connected to a LV distribution grid as described in (Rivera et al. 2011; Xiao et al. 2013). The PV system is based on a three-phase $\mathrm{Y}$-connected cascaded H-bridge topology (Fathi et al., 2009; Jaafar et al., 2008). The analytical model of the PV system and a control strategy for unbalanced operations of the PV system is proposed in this paper. This study gives evidence to the opportunity of using the PV system to compensate for voltage unbalancing. The proposed case study focuses on the control of the converter with unbalanced power generated by the PV modules. The simulations show that each module produces the maximum available power and the converter mitigates the detrimental effects of unbalancing on the distribution network.

\section{Photovoltaic POWER UNIT AND ANALYTICAL REPRESENTATION}

In this section a three phase Y-connected PV power unit is discussed in details. The representation of the system under study is shown in Fig.1. This PV unit is connected to the grid by a cascaded H-bridge converter. Each phase consists of $N$ submodules (SM) connected in series. Each $\mathrm{SM}$ is constituted by a PV module, a unidirectional DC/DC boost converter and a H-bridge converter. The unidirectional DC/DC boost converter enables the MPPT control on the PV module without affecting the operations of the H-bridge converter. All the $\mathrm{H}$-bridge converters are controlled together to balance the currents supplied to the network.

The power system is modeled according to the theory of the symmetrical components. The aim of the proposed formulation is to calculate the energy and power of PV modules. Energy and power are expressed in terms of instantaneous symmetrical and zero-sequence components, which are used in the following section focused on the control strategy. The index $h$ identifies the submodule (i.e. $1 \leq h \leq N$ ), whereas the index $k$ identifies the phase (i.e. $1 \leq k \leq 3$ ).

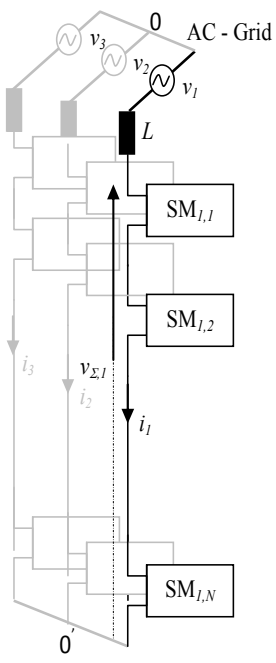

a)

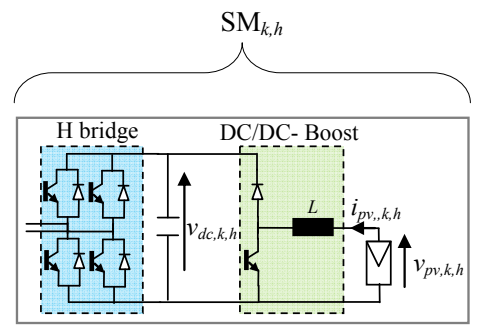

Fig. 1. System under test: a) three-phase cascaded H-bridge based system scheme; b) details on the single submodule $S M_{k, h}$.

\section{A. Preliminary definitions}

Considering a generic set of quantities $y_{k}(t)$ (with $k=1,2,3$ ), the instantaneous symmetrical component (or space vector) $\mathbf{y}$ and the zero-sequence component $y_{0}$ are defined as:

$\mathbf{y}=\frac{2}{3} \sum_{k=1}^{3} y_{k} \mathrm{e}^{j 2 \pi(k-1) / 3} ; y_{0}=\frac{1}{3} \sum_{k=1}^{3} y_{k}$

\section{B. Analytical model of the system}

With reference to the converter diagram of Fig. 1, the AC-side voltage equations for the $k$-th phase can be written as:

$$
\begin{gathered}
v_{k}-v_{\Sigma, k}=L \frac{\mathrm{d} i_{k}}{\mathrm{~d} t} ; \\
v_{\Sigma, k}=\sum_{h=1}^{n} s_{k, h} v_{d c, k, h} .
\end{gathered}
$$

Further equations can be written to link the electrical quantities inside each sub-module SM (see Fig. 1b). With reference to the generic phase $k$, the equations of the submodules of the converter leg are: 


$$
\begin{aligned}
& \frac{\mathrm{d} v_{d c, k, h}}{\mathrm{~d} t}=\frac{1}{C}\left(s_{k, h} i_{k}-\rho_{k, h} i_{p v, k, h}\right) ; \\
& i_{p v, k, h}=f\left(v_{p v, k, h}\right) .
\end{aligned}
$$

where $C$ is the DC capacitance of $h$-th module of $k$-th phase; the quantities $s_{k, h}$ and $\rho_{k, h}$ are the switching functions of the $h$-th submodule and PV module of the $k$ th phase. The switching function $s_{k, h}$ can be equal to $-1,0$ and 1, since all the sub-modules $\mathrm{SM}_{h}$ have a full-bridge configuration and the DC/DC converter is a boost converter, $\rho_{k, h}$ can be equal to 0 and 1 .

The overall switching functions of the $k$-th phase are defined as:

$$
s_{k}=\sum_{h=1}^{n} s_{k, h}
$$

Introducing the transformations (1), eqs. (2) become:

$\frac{\mathrm{d} \mathbf{i}}{\mathrm{d} t}=\frac{\mathbf{v}-\mathbf{v}_{\Sigma}}{L} ;$

$i_{0}=0 \Rightarrow v_{\Sigma, 0}=v_{00^{\prime}}$.

where $\mathbf{i}$ and $i_{0}$ are the symmetrical component and the zero sequence of the AC currents, respectively.

Considering the instantaneous power balance between the $\mathrm{AC}$ and DC sides and neglecting the switching losses, the following equation can be written:

$$
v_{\Sigma, k} i_{k}=\frac{C}{2} \frac{d}{d t}\left(\sum_{h=1}^{n} v_{d c, k, h}^{2}\right)+\sum_{h=1}^{n} v_{p v, h, k} i_{p v, h, k}
$$

Adding together eqs. (5) and introducing the symmetrical and zero sequence components, it is possible to write:

$$
\begin{aligned}
& \frac{\hat{\mathbf{v}}_{\Sigma} \mathbf{i}}{2}+v_{\Sigma, 0} \mathbf{i}=\frac{1}{2} \frac{d}{d t} \mathbf{W}_{d c, \Sigma}+\mathbf{P}_{P V, \Sigma} ; \\
& \frac{1}{2}\left(\mathbf{v}_{\Sigma} \hat{\mathbf{i}}+\hat{\mathbf{v}}_{\Sigma} \mathbf{i}\right)=\frac{d}{d t} W_{d c, \Sigma, 0}+2 P_{P V, \Sigma, 0} ;
\end{aligned}
$$

where with the superimposed $\wedge$ are indicated the conjugates of the vectors and the following positions are considered:

$$
\begin{aligned}
& \mathbf{W}_{d c, \Sigma}=\frac{2}{3} C \sum_{k=1}^{3}\left(\sum_{h=1}^{n} v_{d c, h, k}^{2}\right) e^{j \frac{2 \pi}{3} k} ; \\
& W_{d c, \Sigma, 0}=\frac{1}{3} C \sum_{k=1}^{3}\left(\sum_{h=1}^{n} v_{d c, h, k}^{2}\right) ; \\
& \mathbf{P}_{p v, \Sigma}=\frac{2}{3} \sum_{k=1}^{3}\left(\sum_{h=1}^{n} v_{p v, h, k} \cdot i_{p v, h, k}\right) e^{j \frac{2 \pi}{3} k} ; \\
& P_{p v, \Sigma, 0}=\frac{1}{3} \sum_{k=1}^{3}\left(\sum_{h=1}^{n} v_{p v, h, k} \cdot i_{p v, h, k}\right) .
\end{aligned}
$$

The first equation of (6) represents in terms of symmetrical components the power balance of the three phase system when the power of PV modules is imbalanced. In steady state conditions, the term $v_{\Sigma, 0} \mathbf{i}$ introduces an asymmetrical fluctuation at $2 \omega$ angular frequency on the DC-voltage of each leg and also a DCcomponent. On the contrary, the term $\mathbf{P}_{p v, \Sigma}$ takes into account that an inhomogeneous irradiation produces different powers on each phase. In order to compensate for this unbalancing, the converter has to produce a zerosequence component in the voltage. The second equation gives the instantaneous active power balance between the $\mathrm{PV}$-modules and the grid.

\section{Control Strategy}

The control algorithm can be deduced by the mathematical model represented by (4) and (6). The converter controls the active and reactive power supplied to the grid and compensate for the power unbalancing due to asymmetrical irradiation on the PV modules. The active power control is subordinated to the MPPT strategy of the PV modules. A secondary control consists of voltage balancing of single SM as reported in [10].

The hierarchical control strategy is reported in fig. 2. It shows the two main control block diagrams: active and reactive control (fig.2A) and voltage unbalance compensation control (fig.2B).

The first one calculates the phase voltage reference on the basis of active and reactive power exchanged between the main grid and PV modules of each phase. A decoupled current method in $d$-q rotating frame has been used for calculating the active and reactive reference current. Indeed, the $d-q$ transformation applied to input $\mathrm{L}$ filter leads to following :

$$
\left\{\begin{array}{l}
v_{d}-v_{\Sigma d}=L \frac{d i d}{d t}+\omega L i \\
v_{q}-v_{\Sigma q}=L \frac{d i}{d t}-\omega L i_{d}
\end{array}\right.
$$

where $v_{\Sigma_{d}}$ and $v_{\Sigma_{q}}$ are the $d$-and $q$-axis components of $\mathbf{v}_{\Sigma}$, whereas $i_{d}$ and $i_{q}$ are those of $\mathbf{i}$, respectively. Likewise, $v_{d}$ and $v_{q}$ are the d-and q-axis components of $\mathbf{v}$, respectively. The instantaneous active power $p$ and the instantaneous reactive power $q$ can be expressed as

$$
\left\{\begin{array}{l}
p=v_{d}^{i} d \\
q=v_{d}^{i} q
\end{array}\right.
$$

where the line space vector voltage $\mathbf{v}$ is oriented along the $d$-axis of rotating stator frame, $v_{q}=0$. This allows obtaining that the active and reactive power can be controlled independently as result of the control of $i_{d}$ and $i_{q}$ current components, respectively.

Assuming steady-state conditions and knowing $P_{p v, \Sigma, 0}$ from the MPPT control on each sub-module, the symmetrical $d-q$ current and voltage can be calculated from eq. (8) and the $2^{\text {nd }}$ equation of (6). Separating the complex equations in $d-q$ components, it is:

$$
\left\{\begin{array}{l}
i_{d}^{r e f}=k_{p}\left(W_{d c, \Sigma, 0}^{r e f}-W_{d c, \Sigma, 0}\right)+k_{i} \int_{0}^{t}\left(W_{d c, \Sigma, 0}^{r e f}-W_{d c, \Sigma, 0}\right) d t+\frac{2 P_{P V, \Sigma, 0}}{3 v_{d}}(9) \\
i_{q}^{r e f}=0
\end{array}\right.
$$




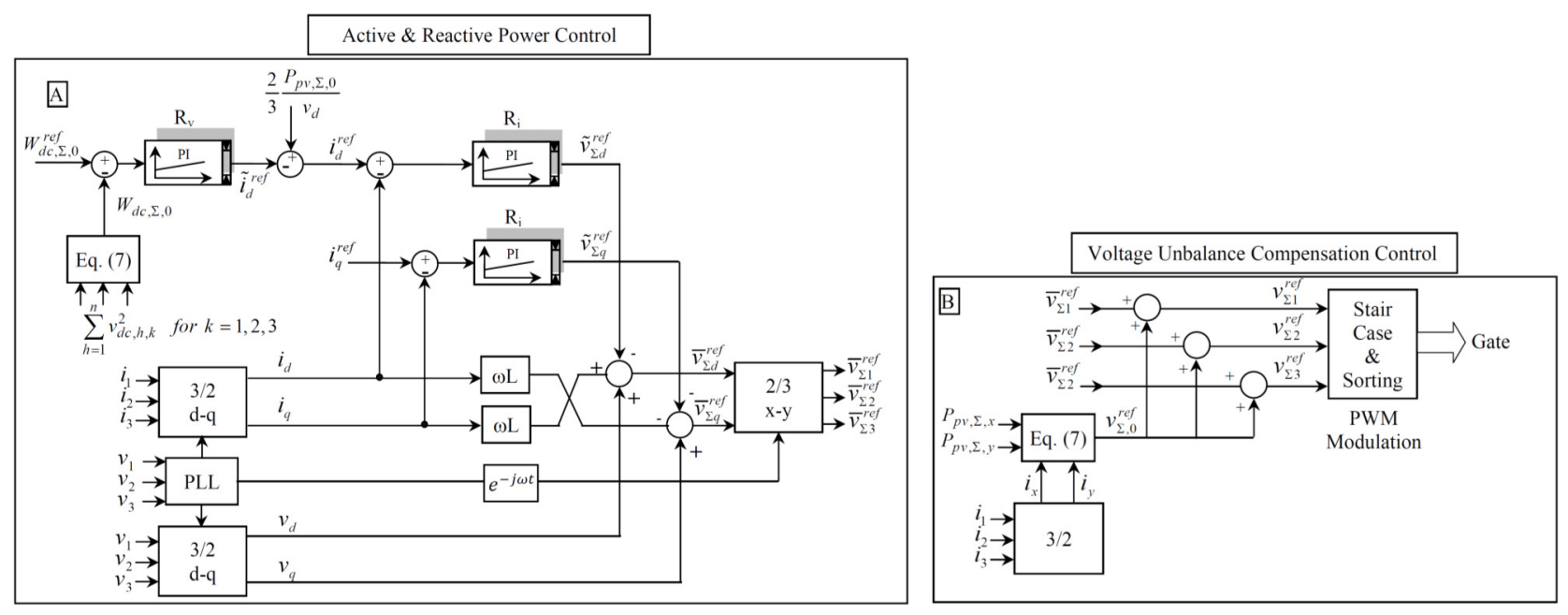

Fig. 2. Diagram block of the control strategy: a) Active and reactive power control; b) Voltage unbalance compensation control

The output of a PI-controller on $W_{d c, \Sigma, 0}$ feedback, $\tilde{i}_{d}^{r e f}$, may be added to the active power requested by the PV source. This allows to take into account the model approximations of eq.(6) in terms of components power losses (capacitance, switching devices, etc.), and the instantaneous voltage variation on DC-capacitors of any SM of each phase. The DC-energy $W_{d c, \Sigma, 0}^{r e f}$ reference, is evaluated on the basis of DC-voltage set point on each sub-module of each phase as reported in (7).

$$
\left\{\begin{array}{l}
\tilde{v}_{d}^{r e f}=k_{p i}\left(i_{d}^{r e f}-i_{d}\right)+k_{i i} \int_{0}^{t}\left(i_{d}^{r e f}-i_{d}\right) \\
\tilde{v}_{q}^{r e f}=k_{p i}\left(i_{q}^{r e f}-i_{q}\right)+k_{i i} \int_{0}^{t}\left(i_{q}^{r e f}-i_{q}\right) \\
\bar{v}_{d}^{r e f}=v_{d}+\omega L i_{q}+\tilde{v}_{d}^{r e f} \\
\bar{v}_{q}^{r e f}=-\omega L i_{d}+\tilde{v}_{q}^{r e f}
\end{array}\right.
$$

The output of $d-q$ PI current controller, summed to the compensation voltages along the $d-q$ axis and the main line voltage, evaluates the $d-q$ voltage reference as reported in (10). The compensation voltages are calculated on the basis of $3 / 2$ and $d-q$ transformation by means of the line phase angle voltage identification (Phase Locked Loop - PLL). Finally the 2/3 transformation allow to calculate the three converter line voltages, $\bar{v}_{\Sigma 1}^{r e f}, \bar{v}_{\Sigma 2}^{r e f}, \bar{v}_{\Sigma 3}^{r e f}$. In order to obtain these references, a modified version of nearest level control (NLC) (Qingrui and Zheng, 2011) has been used. In particular, the number of modules to be connected is chosen using the NLC. Then, an additional cell is connected and a PWM at $1 \mathrm{kHz}$ is implemented on this cell. The voltage balancing of the cells is obtained by means of a sorting algorithm (Saeedifard and Iravani, 2010).
The dynamic behavior of control algorithm is expressed by the closed loop transfer function of diagram block depicted in fig.2A. The direct and quadrature closed loops are dynamically independent thanks to $d, q$ voltage compensation. Thus, the closed loop transfer function $\mathcal{W}(s)$ of overall control refereed to $d$-current component is given:

$$
\mathcal{W}(s)=\frac{w_{d c, \Sigma, 0}(s)}{w_{d c, \Sigma, 0}^{r e f}(s)}=\frac{\mathcal{W}_{0}(s)}{1+\mathcal{W}_{0}(s)}
$$

where the open loop transfer function $\mathcal{W}_{0}(s)$ is obtained by cascaded transfer functions of inner current control loop, $\mathcal{W}_{i_{d}}(s)$, the PI dc-voltage controller, $\mathrm{R}_{w}(s)$, and the equivalent dc-voltage, $\mathcal{W}_{w_{d c, \Sigma, 0}}$, as reported in the following :

$$
\begin{gathered}
\mathcal{W}_{0}(s)=\mathrm{R}_{w}(s) \mathcal{W}_{i_{d}}(s) \mathcal{W}_{w_{d c, \Sigma, 0}}(s) \\
\mathcal{W}_{i_{d}}(s)=\frac{I_{d}(s)}{I_{d}^{r e f}(s)}=\frac{s k_{p i}+k_{i i}}{s^{2} L+s k_{p i}+k_{i i}} \\
\mathrm{R}_{w}(s)=\frac{s k_{p w}+k_{i w}}{s} \\
\mathcal{W}_{w_{d c, \Sigma, 0}}(s)=\frac{w_{d c, \Sigma, 0}(s)}{I_{d}(s)}=\frac{0.5 v_{d}}{s}
\end{gathered}
$$

The $\mathcal{W}_{i_{d}}(s)$ is obtained by the dynamic equations of (8) and (10), taking into account the $d, q$ voltage compensation; the $\mathcal{W}_{w_{d c, \Sigma, 0}}(s)$, instead, is obtained by dcac power balance expressed by the $2^{\text {nd }}$ equation of (6). It has been supposed that quadrature current, $\mathrm{i}_{q}$, is equal to zero. 
In the same way, the closed loop transfer function of quadrature current, $\mathcal{W}_{i_{q}}(s)$, is obtained also by the dynamic equations of (8) and (10):

$$
\mathcal{W}_{i_{q}}(s)=\frac{I_{q}(s)}{I_{q}^{r e f}(s)}=\frac{s k_{p i}+k_{i i}}{s^{2} L+s k_{p i}+k_{i i}}
$$

The unbalance voltage compensation control is depicted in fig.2B, where the evaluation of the zero-sequence voltage for the compensation of power unbalancing due to asymmetrical condition can be calculated from the $1^{\text {st }}$ equation of (6) at steady state. Indeed, imposing the solution at steady state, the $1^{\text {st }}$ equation of (6) is written as:

$$
\frac{\hat{\mathbf{V}}_{\Sigma} \hat{\mathbf{I}}}{2} e^{j 2 \omega t}+\frac{\mathbf{V}_{\Sigma, 0} \mathbf{I}}{2} e^{-j 2 \omega t}+\frac{\hat{\mathbf{V}}_{\Sigma, 0} \mathbf{I}}{2}=\frac{1}{2} \frac{d}{d t} \widetilde{\mathbf{W}}_{d c, \Sigma}+\mathbf{P}_{P V, \Sigma} ;
$$

where with the superimposed $\sim$ the mean value has been indicated.

Imposing the equality of the DC-component of (11), the real and imaginary part can be obtained as:

$$
\begin{gathered}
v_{\Sigma, 0, x} i_{x}+v_{\Sigma, 0, y} i_{y}=2 P_{p v, \Sigma, x} ; \\
v_{\Sigma, 0, x} i_{y}-v_{\Sigma, 0, y} i_{x}=2 P_{p v, \Sigma, y} ;
\end{gathered}
$$

where the amplitude and angle of $\mathbf{V}_{\Sigma, 0}$ can be calculated as:

$$
\left\{\begin{array}{l}
\mathbf{V}_{\Sigma, 0}=\frac{2}{i} \sqrt{\left(\mathbf{P}_{P V, \Sigma, x}\right)^{2}+\left(\mathbf{P}_{P V, \Sigma, y}\right)^{2}} \\
\varphi_{0}=\arctan \left(\frac{\mathbf{P}_{P V, \Sigma, x} \cdot i_{y}-\mathbf{P}_{P V, \Sigma, y} \cdot i_{x}}{\mathbf{P}_{P V, \Sigma, x} \cdot i_{x}+\mathbf{P}_{P V, \Sigma, y} \cdot i_{y}}\right)
\end{array}\right.
$$

The real and imaginary part of $\mathbf{P}_{p v, \Sigma}$ can be expressed in terms of the instantaneous power of each phase:

$$
\begin{aligned}
& P_{p v, \Sigma, x}=p_{p v, 1}-\frac{\sum_{k} p_{p v, k}}{3} ; \\
& P_{p v, \Sigma, y}=\frac{\sqrt{3}}{3}\left(p_{p v, 2}-p_{p v 3}\right) .
\end{aligned}
$$

The instantaneous power of each phase $p_{p v, 1}, p_{p v, 2}$, $p_{p v, 3}$ are given by the sum of instantaneous power of all the PV modules in that phase.

Finally, the zero sequence voltage is summed to line voltage reference, calculated by the active and reactive power control, for obtaining the line voltages reference $v_{\Sigma 1}^{r e f}, v_{\Sigma 2}^{r e f}, v_{\Sigma 3}^{r e f}$. The PWM stair-case modulation technique combined with sorting algorithm has been implemented (Iannuzzi et al., 2013) for calculating the gate-driver duty-cycles.

In order to understand the requirements for the converter to produce a zero-sequence component of the voltage, the previous equations are simplified considering only the first harmonics of voltage and current. The voltage has positive and zero sequences, whose peaks are $V_{\Sigma}$ and $V_{\Sigma, 0}$ respectively. The current has only a positive sequence, $I$, due to the Y-connection. The instantaneous power generated by the generic leg of the converter can be expressed as follows:

$$
\begin{aligned}
p_{k}(t)= & {\left[V_{\Sigma} \cos \left(\omega t-\frac{2 \pi}{3} k\right)+V_{\Sigma, 0} \cos \left(\omega t+\varphi_{0}\right)\right] . } \\
& \cdot I \cos \left(\omega t-\frac{2 \pi}{3} k-\varphi\right)
\end{aligned}
$$

where $\varphi$ is the phase of the current. The previous equation leads to the following active power:

$$
p_{k}(t)=\frac{1}{2} V_{\Sigma} I \cos \varphi+\frac{1}{2} V_{\Sigma, 0} I \cos \left(\varphi+\varphi_{0}-\frac{2 \pi}{3} k\right)=\frac{P}{3}+\Delta P_{k}
$$

From (13) it is clear that:

$$
\sum_{k=1}^{3} \Delta P_{k}=0
$$

Therefore, only two phase powers can be selected arbitrarily, e.g. $\Delta P_{1}$ and $\Delta P_{2}$. Hence, from (14) and (15) it is possible to evaluate the magnitude and phase of the zero sequence component of the voltage for each given values of $\Delta P_{1}$ and $\Delta P_{2}$ :

$$
\left\{\begin{array}{l}
\mathbf{V}_{\Sigma, 0}=\frac{4}{\sqrt{3} I_{\max }} \sqrt{\Delta P_{1}^{2}+\Delta P_{1} \Delta P_{2}+\Delta P_{2}^{2}} \\
\varphi_{0}=-\varphi-\arctan \left(\frac{1}{\sqrt{3}}\left(\frac{\Delta P_{2}}{\Delta P_{1}}+\frac{1}{2}\right)\right)
\end{array}\right.
$$

The zero-sequence component of the voltage is added to the positive sequence component and its phase depends on both the power unbalance required and the phase of the current. In the worst case, the peak value of the voltage has to be $V_{\Sigma, \max }+V_{0, \text { max }}$. In order to avoid overmodulation, the duty-cycle of the $\mathrm{DC} / \mathrm{DC}$ converter should be adjusted to increase the DC-link voltage of the H-bridges. The duty ratio depends on the irradiation. For the case-study, the maximum power point voltage across each modules varies between $19.3 \mathrm{~V}$ and $21.9 \mathrm{~V}$ when the irradiation varies between $100 \mathrm{~W} / \mathrm{m}^{2}$ and $1000 \mathrm{~W} / \mathrm{m}^{2}$. Fig.3 shows the boost ratio of the DC/DC converter for any variation of the power delivered by two phases in the range $\pm 20 \%$ of the nominal power of the PV module. According to the classic theory of $\mathrm{DC} / \mathrm{DC}$ boost converters and (12), the duty-cycle of the boost converter has to be comprised between two conical surfaces to achieve at the same time the MPPT and the current balancing. In Fig. 3 these surfaces are reported as function of power unbalances in per unit defined as:

$$
\begin{aligned}
& \delta P_{1}=\frac{3 \Delta P_{1}}{P} ; \\
& \delta P_{2}=\frac{3 \Delta P_{2}}{P} .
\end{aligned}
$$

\section{CASE STUDY}

A PV source connected to a $\mathrm{LV}$ grid at $400 \mathrm{~V}$ and 50 $\mathrm{Hz}$ is considered. Table I shows possible different configurations of PV-modules on the basis of the number of SMs and the rated voltage of the MosFETs. Assuming 
$V$ as the grid line-to-line voltage, the minimum DC-link voltage can be calculated according to:

$$
v_{d c}=\frac{V}{N \sqrt{3}} \sqrt{2}
$$

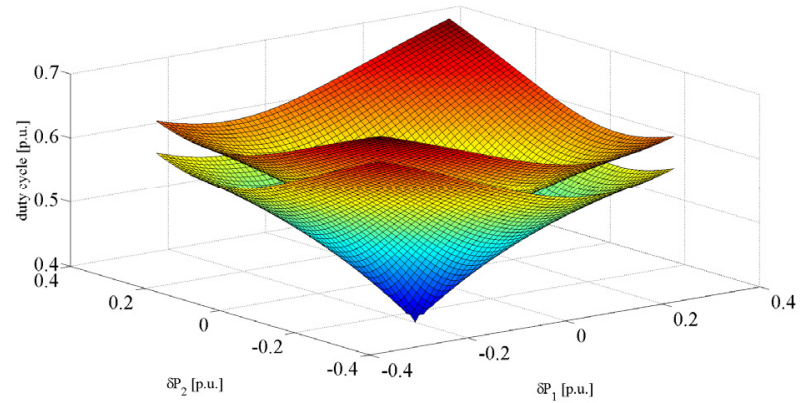

Fig. 3. Duty-cycle of the DC/DC converter of the PV module needed for power unbalancing with zero-sequence voltage injection.

TABLE I - DESIGN EXAMPLES OF CELLS FOR $400 \mathrm{~V}$ GRID-TIED CASCADED H-BRIDGE CONVERTER FOR PV

\begin{tabular}{|c|c|c|c|}
\hline $\begin{array}{c}N \\
{[-]}\end{array}$ & $\begin{array}{c}\text { Mosfet voltage } \\
{[\mathrm{V}]}\end{array}$ & $\begin{array}{c}v_{D C} \\
{[\mathrm{~V}]}\end{array}$ & $\begin{array}{c}v_{P V} \text { range } \\
{[\mathrm{V}]}\end{array}$ \\
\hline 12 & 55 & 27 & $10-41$ \\
\hline 10 & 100 & 33 & $12-47$ \\
\hline 8 & 100 & 41 & $16-65$ \\
\hline
\end{tabular}

The voltage generated by the PV modules depends on the solar irradiation and the temperature. The required power of the PV system is reached by connecting in parallel a suitable number of PV-modules.

The characteristic of the PV-modules used in this paper is shown in Fig. 4. This characteristic has been experimentally evaluated using the panel Aluminum Tedlar 125M36. This panel has a peak power of $42.5 \mathrm{~W}$ at $21.9 \mathrm{~V}$ and an open circuit voltage of $25.8 \mathrm{~V}$.

On the basis of this characteristic, the converter has been designed with 10 series SM per phase. Any SM has $10 \mathrm{PV}$ modules connected in parallel. Therefore, the total PV system has a peak power of $12.7 \mathrm{~kW}$.

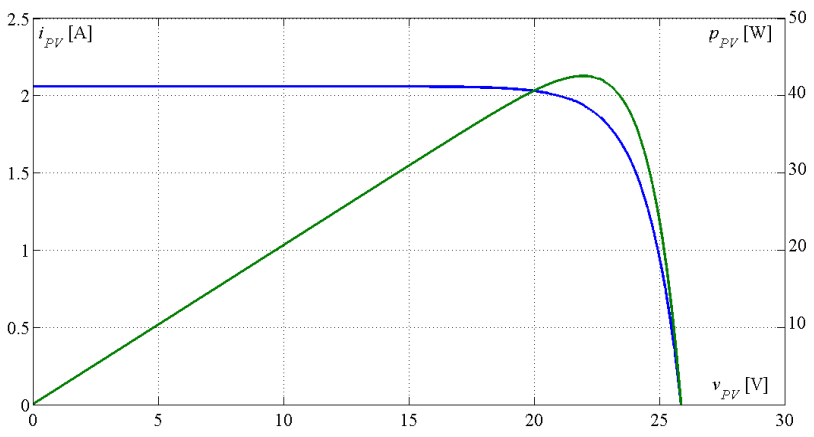

Fig. 4. Electrical characteristic of the PV module used in the simulations.

\section{NUMERICAL RESULTS}

The PV power system has been simulated in Matlab $^{\circledR} /$ Simulink $^{\circledR}$ environment. The operations of the proposed PV system under homogeneous irradiation conditions have been already shown in (Iannuzzi at al., 2013). In this paper a case of inhomogeneous insolation on each phase has been considered to verify the capability of the proposed converter of supplying balanced currents to the network. For this reason, in the following analyses, only the cases related to shaded modules were evidenced.

According to the previous considerations, in the following simulations all the modules of the phase 1 are fully irradiated with $1000 \mathrm{~W} / \mathrm{m}^{2}$. Five out of ten modules of phase 2 are irradiated with $600 \mathrm{~W} / \mathrm{m}^{2}$ and the others are fully irradiated. Seven out of ten modules of phase 3 are shaded and irradiated with $400 \mathrm{~W} / \mathrm{m}^{2}$, while the other three modules are fully irradiated. In these hypotheses, the available total power is about $10 \mathrm{~kW}$. In Table II the values of irradiation on any submodules are synthetically detailed.

TABLE II - VALUES OF IRRADIATION ON SYSTEM'S SUBMODULE [W/m²] ( $h$ INDEX OF SUBMODULE, $k$ INDEX OF PHASE)

\begin{tabular}{|c|c|c|c|}
\hline$h$ & $k=1$ & $k=2$ & $k=3$ \\
\hline 1 & 1000 & 1000 & 1000 \\
\hline 2 & 1000 & 1000 & 1000 \\
\hline 3 & 1000 & 1000 & 1000 \\
\hline 4 & 1000 & 1000 & 400 \\
\hline 5 & 1000 & 1000 & 400 \\
\hline 6 & 1000 & 600 & 400 \\
\hline 7 & 1000 & 600 & 400 \\
\hline 8 & 1000 & 600 & 400 \\
\hline 9 & 1000 & 600 & 400 \\
\hline 10 & 1000 & 600 & 400 \\
\hline
\end{tabular}

Figure 5 shows the total generated power, which reaches its maximum value in less than 1 second with the MPPT control. The starting transient depends on the voltage regulator, $R_{v}$ of Fig. 2 . The constants of this regulator have been set as a compromise to achieve a good dynamic and limited oscillations during transient. In order to verify the capability of balancing the currents, the simulation starts with different initial voltages on the DClink capacitances, with values from $39 \mathrm{~V}$ to $51 \mathrm{~V}$. In Fig. 6 the mean voltage of the capacitances of each phase are reported. Then, in Fig. 7 the minimum (solid line) and maximum (dotted line) module voltages are reported at steady state. As resulting from Fig. 6 the voltages across the capacitors are completely balanced within $600 \mathrm{~ms}$. Due to the inhomogeneous irradiation, the voltages across the capacitors have different average values and, in particular, the lower voltage corresponds to the shaded modules, while the higher voltage corresponds to the fully irradiated modules. Anyway, the control is capable of maintaining the different voltage values really close the ones to the others.

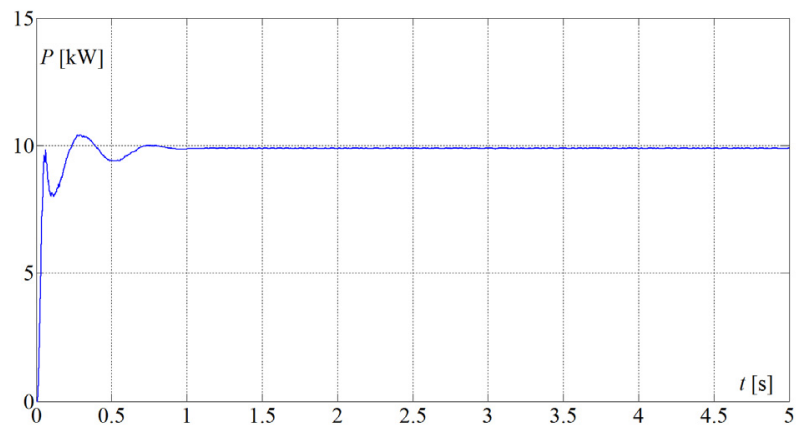

Fig. 5. Total power generated by the PV system. 
If there is no control of the zero-sequence component of the voltage, the currents injected into the grid are not symmetrical. In Fig. 8 these currents are reported and it's clear how the current of the shaded phase (black line) is lower than the others. The negative component of the current is $21 \%$.

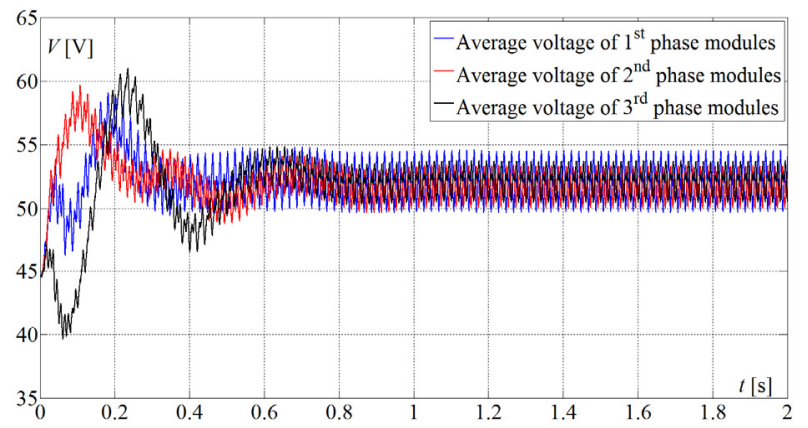

Fig. 6. Average voltages of the modules of the three phases

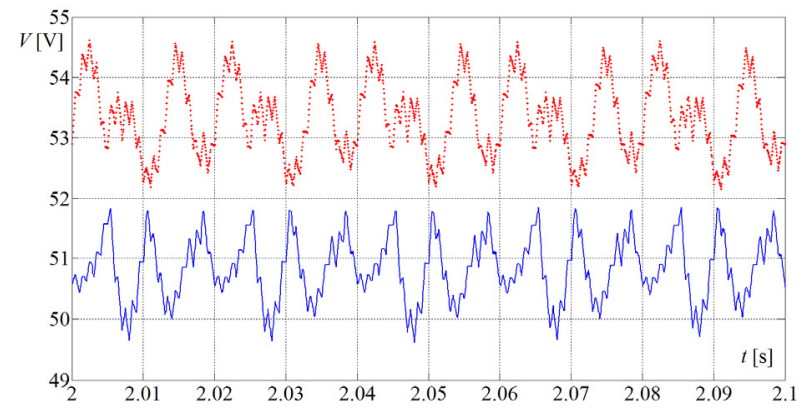

Fig. 7. Minimum and maximum module voltages

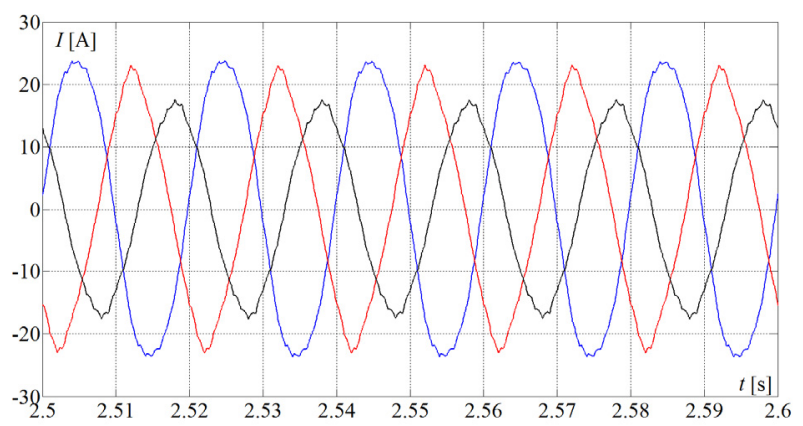

Fig. 8. Currents injected in the grid without the balancing control

Then, the zero-sequence component of the voltage calculated with (12) has been applied to the control and Fig. 9 shows the currents injected into the network in this case. The negative component is now lower than $1 \%$, while there are no changes in the total generated power. The magnitudes of the positive, negative and zero sequence components of the currents and the voltages are reported for both the uncontrolled and controlled algorithms in Tab.III.

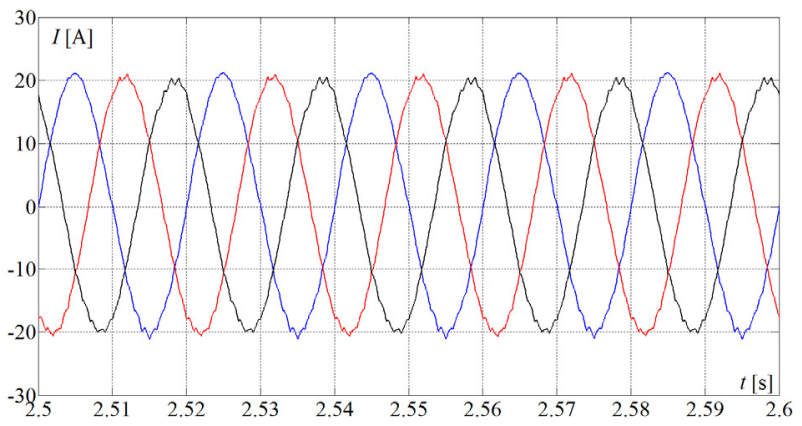

Fig. 9. Current injected in the grid with the balancing control

The magnitude and phase of the zero-sequence voltage calculated by the control system are reported in Figs. 10 and 11. Immediately after the activation of the control, the magnitude of the zero-sequence component of the voltage is very high, also because of the power transient but, at steady state, their values is suitable to completely compensate the negative component of the current. If the required zero-component calculated with (15) is higher than the maximum available for each phase, the zero component applied by the control is the maximum allowable and the compensation is not perfect. As it is shown in Fig.11, for the simulated case, the zero sequence required for a perfect compensation is a little bit lower than the maximum allowed.

TAB. III CURRENT AND VOLTAGE COMPONENTS WITH AND WITHOUT ZERO SEQUENCE CONTROL.

\begin{tabular}{|c|c|c|c|c|}
\hline & \multicolumn{2}{|c|}{$\begin{array}{c}\text { No active } \\
\text { zero-sequence control }\end{array}$} & \multicolumn{2}{|c|}{$\begin{array}{c}\text { Active } \\
\text { zero-sequence control }\end{array}$} \\
\hline sequence & $\begin{array}{l}\text { Line } \\
\text { current }\end{array}$ & $\begin{array}{c}\text { Line } \\
\text { voltage }\end{array}$ & $\begin{array}{l}\text { Line } \\
\text { current }\end{array}$ & $\begin{array}{l}\text { Line } \\
\text { voltage }\end{array}$ \\
\hline Positive & $20.5 \mathrm{~A}$ & $332.8 \mathrm{~V}$ & $20.3 \mathrm{~A}$ & $332.6 \mathrm{~V}$ \\
\hline Negative & $4.50 \mathrm{~A}$ & $14.1 \mathrm{~V}$ & $0.16 \mathrm{~A}$ & - \\
\hline Zero & - & $35.6 \mathrm{~V}$ & - & $107.8 \mathrm{~V}$ \\
\hline
\end{tabular}

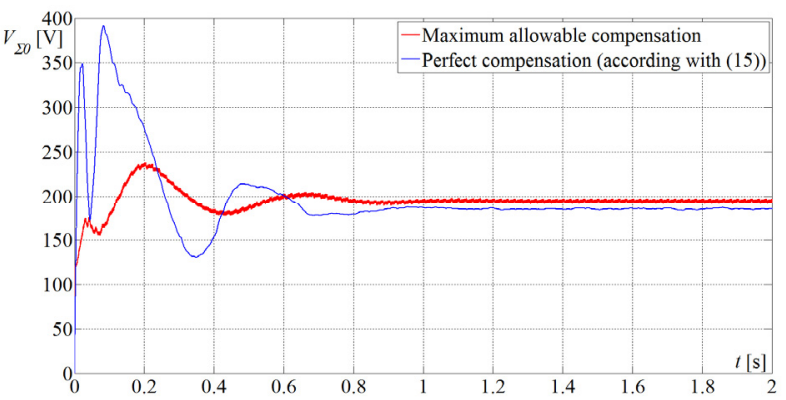

Fig. 10. Magnitude of the zero-sequence voltage used for the compensation of the irradiance unbalancing 


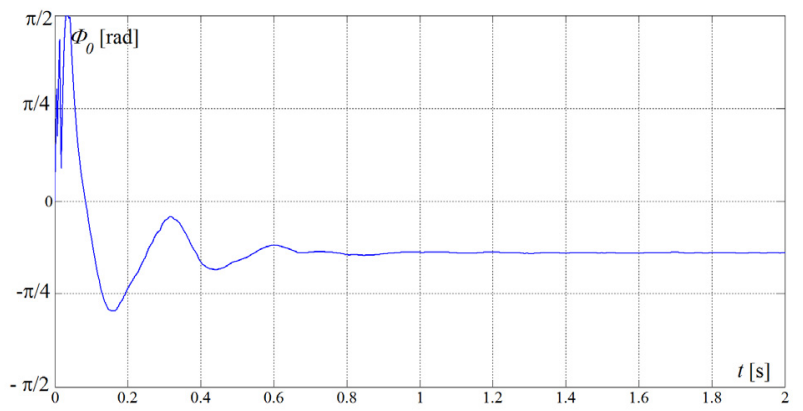

Fig. 11. Phase angle of the zero-sequence voltage used for the compensation of the irradiance unbalancing

Analyzing the results of numerical simulations it is also possible to verify that the condition on the duty cycles given in Fig. 3 are respected at steady state. In Fig. 12 the values of $\delta P_{1}$ and $\delta P_{2}$ are reported together with the duty cycles of three panels (one per each phase) with different irradiation.

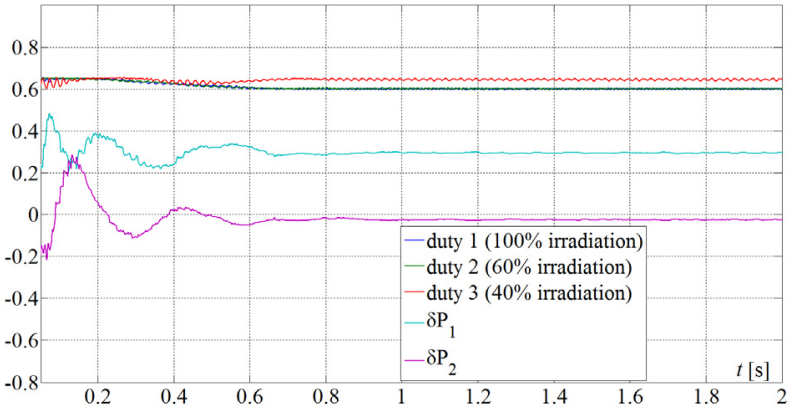

Fig. 12. $\delta P_{1}$ and $\delta P_{2}$ and duty cycles during the simulation

From the analysis of Fig. 12 it is clear how the low irradiated panels work at higher duty cycle. Anyway, the difference among the duty cycles is limited because for PV panels, MPP voltage is little sensitive to irradiation changes.

\section{CONCLUSIONS}

In recent years, many residential buildings around the world have increasingly used photovoltaic systems as an integrative power source. This development has given momentum for research in the area of photovoltaic generation and in particular the analysis of unbalanced irradiation on photovoltaic modules. The paper analyzed a three phase photovoltaic system connected to a LV distribution grid with inhomogeneous irradiation on the modules. The modules are connected to the grid by means of a cascaded H-bridge converter, suitable for the integration of modules in the façade of the buildings. A mathematical model of the system has been formulated to define a new control strategy suitable for the balancing of currents in the case of inhomogeneous irradiation on the photovoltaic modules. The proposed model is based on the symmetrical components of the system quantities. The zero-sequence component of voltage is controlled to compensate for the power unbalancing between the phases of the converter. From the analysis, the relation between the magnitude of the zero-sequence component of the voltage and the level of power unbalancing has been calculated. As a consequence, the operative limits in terms of minimum and maximum duty-cycle of DC-DC boost converter have been assessed. In order to demonstrate the validity of the proposed converter, a numerical simulator of a photovoltaic system has been designed. The results of the numerical simulations give full evidence of the current balancing capabilities of the converter for a wide range of irradiation unbalancing of the photovoltaic modules.

\section{REFERENCES}

Caldon R., Coppo M., and Turri R., "A network voltage control strategy for LV inverter interfaced users", in Proc. $8^{\text {th }}$ Mediterranean Conf. Power Gener., Transm., Distrib. and Energy Conv. MEDPOWER 2012, pp. 1-5, 2012.

Caramia P., Carpinelli G., Pagano M., and Varilone P., "Probabilistic three-phase load flow for unbalanced electrical distribution systems with wind farms", IET Renew. Power Gener., vol. 1, issue 2, pp. 115$122,2007$.

Chavarría J., Biel D., Guinjoan F., Meza C., Negroni J.J., "EnergyBalance Control of PV Cascaded Multilevel Grid-Connected Inverters Under Level-Shifted and Phase-Shifted PWMs", in IEEE Tr. On Industrial Electronics, vol. 60, issue 1, January 2013, pp.: 98-111.

Fathi S.H., Hosseini Aghdam M.G., Zahedi A., Gharehpetian G.B., "Optimum regulation of DC sources in cascaded multi-level inverters", Compel-Int. J. Comp. Math. Electr. Electron. Eng., vol. 28, issue 2, pp. 385-395, 2009.

Gallo D., Langella R., Testa A., Hernández J. C., Papič I., Blažic B., and Meyer J., "Case studies on large PV plants: harmonic distortion, unbalance and their effects", in Proc. IEEE Power and Energy Soc. General Meeting PES 2013, pp. 1-5, 2013.

Iannuzzi D., Piegari L., and Tricoli P., "A novel PV-modular multilevel converter for building integrated photovoltaics", in Proc. $8^{\text {th }}$ Int. Conf. and Exhibition on Ecological Vehicles and Renewable Energies EVER 2013, pp.1,7, 27-30 March 2013.

Jaafar I., Ammar F. B., Elleuch M., "Modelling and control of cascaded multilevel converters for dynamic compensation", Compel-Int. J. Comp. Math. Electr. Electron. Eng., vol. 27, issue 5, pp. 1144-1161, 2008.

Malinowski M., Gopakumar K., Rodriguez J., Pérez M.A., “A Survey on Cascaded Multilevel Inverters", in IEEE Tr. On Industrial Electronics, vol. 57, issue 74, July 2010, pp.: 2197-2206.

Morya A.K., Shukla A. Doolla S., "Control of Grid Connected Cascaded H-Bridge Multilevel Converter During Grid Voltage Unbalance for Photovoltaic Application", IECON 2013 - 39th Annual Conference of the IEEE, 10-13 November 2013, pp:7990-7995.

Qingrui Tu; Zheng Xu, "Impact of Sampling Frequency on Harmonic Distortion for Modular Multilevel Converter," IEEE Transactions on Power Delivery, vol.26, no.1, pp.298,306, Jan. 2011

Rivera S., Kouro S., Wu B., Leon J. I., Rodríguez J., and Franquelo L. G., "Cascaded H-Bridge multilevel converter multistring topology for large scale photovoltaic systems", in Proc. 2011 IEEE Int. Symposium Ind. Electron. ISIE 2011, pp. 1837-1844, 27-30 June 2011.

Rodríguez J., Lai J.S., Peng F.Z., "Multilevel Inverters: A Survey of Topologies, Controls, and Applications", in IEEE Tr. On Industrial Electronics, vol. 49, issue 4, August 2002, pp.: 724-738.

Saeedifard, M.; Iravani, R., "Dynamic Performance of a Modular Multilevel Back-to-Back HVDC System," IEEE Transactions on Power Delivery, , vol.25, no.4, pp.2903,2912, Oct. 2010 
Vechiu I., Curea O., Llaria A., and Camblong H., "Control of power converters for microgrids", Compel-Int. J. Comp. Math. Electr. Electron. Eng., vol. 30, issue 1, pp. , 300-309, 2011.

Villanueva E., Correa P., Rodríguez J., Pacas M., "Control of a SinglePhase Cascaded H-Bridge Multilevel Inverter for Grid-Connected Photovoltaic Systems", in IEEE Tr. On Industrial Electronics, vol. 56, issue 11, November 2009, pp.: 4399-4406.
Xiao B., Hang L., Riley C., Tolbert L. M., and Ozpineci B., "ThreePhase modular cascaded H-bridge multilevel inverter with individual MPPT for grid-connected photovoltaic systems", in Proc. $28^{\text {th }}$ Annual IEEE Applied Power Electron. Conf. and Exposition APEC 2013, pp. 468-474 17-21 March 2013. 